\title{
VULNERABILIDAD, RECONOCIMIENTO MUTUO Y ÉTICA AMBIENTAL
}

\author{
MANUEL APARICIO PAYÁ \\ Profesor de Filosofía \\ Universidad de Murcia \\ manuel.aparicio@um.es
}

RESUMEN: En este trabajo exploramos la relevancia que, para la ética discursiva, posee la categoría de reconocimiento mutuo en el ámbito de una ética del medioambiente. Partimos de la intrínseca vulnerabilidad que caracteriza a los seres humanos, agravada en la era del Antropoceno por la vulnerabilidad ecológica, consecuencia de los daños medioambientales provocados por la acción humana. Después de una breve presentación de la noción de reconocimiento recíproco propuesta por este enfoque ético (Apel, Habermas, Cortina), analizamos la conexión de esta noción con los principios de no maleficencia y de responsabilidad de la ética medioambiental.

PALABRAS ClAVE: ética del diálogo, reconocimiento, vulnerabilidad, ética ambiental, principio de no maleficencia, principio de responsabilidad.

ABSTRACT: In this work we explore the relevance that, for discursive ethics, has the category of mutual recognition in the field of environmental ethics. We start from the intrinsic vulnerability that characterizes human beings, aggravated in the era of the Anthropocene by the ecological vulnerability, consequence of environmental damages caused by human action. After a brief presentation of the notion of reciprocal recognition proposed by this ethical approach (Apel, Habermas, Cortina), we analyze the connection of this notion with the principles of nonmaleficence and responsibility of environmental ethics.

KEYWORDS: discursive ethics, recognition, vulnerability, environmental ethics, principle of nonmaleficence, principle of responsibility.

SUMARIO: I. INTRODUCCIÓN - II. INTERDEPENDENCIA, VULNERABILIDAD Y OBLIGACIÓN MEDIOAMBIENTAL - III. DAÑO AMBIENTAL, RECONOCIMIENTO MUTUO Y PRINCIPIO DE NO MALEFICENCIA - IV. PRINCIPIO DE RESPONSABILIDAD Y RECONOCIMIENTO MUTUO - V. CONCLUSIÓN - VI. BIBLIOGRAFÍA.

\section{INTRODUCCIÓN}

En el prólogo a La condición humana, con motivo del primer paso efectivo dado en la carrera espacial, Hanna Arendt recuerda una frase esculpida en el monumento fúnebre de un científico ruso: "La humanidad no permanecerá atada para siempre a la Tierra" (Arendt, 2015: 14). La célebre pensadora era consciente en dicha obra de que los conocimientos científicos y técnicos, los cuales habían comenzado a permitir exitosamente la superación de la condición terrestre humana, podían también contribuir, sin embargo, a «destruir toda la vida orgánica de la Tierra», incluida, por tanto, la vida de todos los miembros de la especie humana. De ahí que entienda que dichos conocimientos científico-técnicos deben estar sujetos al ámbito del 
conjunto de la comunidad política y sometidos al poder del discurso (Arendt, 2015: 15-17) ${ }^{1}$. Tan grave advertencia acerca del poder destructor alcanzado históricamente por el saber tecnocientífico humano tenía ya diversos antecedentes por parte de los propios científicos: por ejemplo, unos años antes, en 1947, subrayando los peligros de la energía nuclear, se había creado el denominado Reloj del Apocalipsis, con la pretensión de marcar el tiempo que ha de dar paso al fin físico de la humanidad. Resulta llamativo que, apenas poco más del medio siglo transcurrido desde el citado escrito de Arendt, otro científico, el físico Stephen Hawking, haya profetizado la inmediata cercanía de dicho momento final, salvo que la especie humana sea capaz, en virtud de las oportunidades pragmáticas abiertas por los conocimientos científicotécnicos adquiridos, de abandonar nuestro planeta ${ }^{2}$. Las razones a las que responde tan urgente necesidad parecen ser de índole ético-política: la acción humana sobre el medio ambiente ha dado lugar a la aparición del cambio climático y a la no menos alarmante desaparición o deterioro de los recursos naturales, lo cual ya está amenazando no solo la supervivencia de especie humana, sino, en una escala global, al conjunto de la vida sobre la Tierra. La constatación científica de la creciente vulnerabilidad de nuestro planeta, debido a los daños producidos por la acción humana, constituye una llamada acuciante a la necesidad de abordar el reto de conservación de la vida terrestre desde la extensión de la conciencia moral medioambientalista y la transformación de las instituciones políticas ${ }^{3}$, como base de una nueva relación de los seres humanos con los seres no humanos, vivos o inertes.

La cada vez más patente crisis medioambiental ha exigido la transformación de una reflexión ética centrada, desde la antigüedad, en la relación práctica entre los seres humanos, a una ética que amplíe sus perspectivas y tenga en cuenta también las obligaciones morales hacia los seres vivos y el resto de la naturaleza. En la construcción de este nuevo paradigma ético se han dado varios planteamientos teóricos: frente a la versión antropocéntrica, más centrada en poner de manifiesto las graves repercusiones de la crisis ecológica en el futuro humano y en la exclusiva responsabilidad moral de los seres humanos para contener y revertir dicho deterioro ambiental, se han alzado posiciones biocentristas, que proponen la vida como valor nuclear, equiparando de este modo la vida humana con la de las diferentes especies biológicas, o ecocentristas, desde las que se toma en consideración el valor intrínseco del conjunto de la naturaleza (Siurana, 2009: 79-80; Gómez-Heras, 1997; Cortina 2009b: 32-36).

La ética del discurso, por su parte, profundiza en la idea defendida por Arendt de que el discurso «hace del hombre un ser único» (Arendt, 2015: 16). Desarrollada inicialmente por Karl Otto Apel y Jürgen Habermas, y continuada entre nosotros, con modificaciones, por la profesora Adela Cortina, dicha ética adopta un enfoque antropocéntrico (Cortina, 1990; Siurana, 2009) en la fundamentación de las obligaciones ecológicas que tenemos los seres humanos. Al trasladar al terreno del discurso racional práctico la problemática medioambiental, generada por una racionalidad instrumental que ha posibilitado un desarrollo científico-técnico -con sus aplicaciones en el mundo económico- que está dañando a escala global la naturaleza, así como la fundamentación de normas encaminadas a asumir la responsabilidad humana ecológica, la ética discursiva puede constituirse como una ética ambiental, es decir, como una ética que

\footnotetext{
1 "Y cualquier cosa que el hombre haga, sepa o experimente solo tiene sentido en el grado en que pueda expresarlo. Tal vez haya verdades más allá del discurso, y tal vez sean de gran importancia para el hombre en singular, es decir, para el hombre en cuanto no sea un ser político, pero los hombres en plural, o sea, los que viven, se mueven y actúan en este mundo, sólo experimentan el significado debido a que se hablan y se sienten unos a otros a sí mismos", (Arendt, 2015: 16-17).

${ }^{2}$ https://elpais.com/elpais/2017/06/27/opinion/1498583554_143323.html (consultado el 15-3-2018).

${ }^{3}$ Entendemos que las instituciones políticas han de regular jurídicamente las instituciones económicas y que, más allá de tal regulación, también las organizaciones económicas han de asumir su responsabilidad ecológica (García Marzá, 1999).
} 
incorpora a los seres de la naturaleza al ámbito de la moralidad humana. Frente a los enfoques biocéntricos o ecocéntricos que, en cierto modo, pretenden diluir al ser humano en el entorno natural, concibiéndolo al modo de un ser vivo más, residente en el mismo; que fundamentan las normas morales medioambientales en una pretendida normatividad natural (Gómez-Heras, 1997: 37-42), la ética discursiva, en sus diferentes versiones, sitúa en la intersubjetividad de la racionalidad práctica, tanto en el campo moral como en el jurídico-político, la fundamentación de las obligaciones humanas con los seres vivos e inertes que pueblan nuestro planeta ${ }^{4}$. En la medida en que la ética discursiva apela a la noción de reconocimiento mutuo entre los participantes en el discurso (Apel, 1985; Habermas, 2000; Cortina, 2009a), quedaría establecida una conexión relevante entre dicha noción y la ética ambiental. En lo que sigue, trataremos de mostrar la relevancia que, para la ética medioambiental, tiene la categoría de reconocimiento. En primer lugar, nos ocupamos de la concepción del reconocimiento en los autores que desarrollan la ética discursiva (Apel, Habermas, Cortina). Después abordamos la conexión entre daño ambiental y reconocimiento mutuo, así como la relación subyacente entre este y el principio de no maleficencia. Finalmente, analizamos la implicación del reconocimiento mutuo en el principio de responsabilidad ecológica.

\section{INTERDEPENDENCIA, VULNERABILIDAD Y OBLIGACIÓN MEDIOAMBIENTAL}

La crisis ecológica producida en lo que se ha denominado como la era del Antropoceno ${ }^{5}$ ha traído como consecuencia que se empiece a tomar conciencia de que «somos colectivamente un agente geológico» (Pelluchon, 2015, 94-95) que modifica, hacia un futuro que parece adelantarse $^{6}$, las condiciones de las que depende la vida. Este cambio cualitativo introducido en el devenir histórico humano marca una diferencia relevante con el resto de las especies biológicas: dejamos de ser meros agentes biológicos y, a través de una cultura centrada en el desarrollo científico-técnico y su aplicación económica, pasamos a convertirnos en una especie biológica capaz de dejar una huella ecológica en el planeta. Este cambio cualitativo implica que «no somos simples criaturas sujetas a la Tierra» (Arendt, 2015: 25), sino que también el medio ambiente terrestre está sujeto a las condiciones creadas por la especie humana ${ }^{7}$. Tal conciencia de la interacción geológica seres humanos-Tierra ${ }^{8}$ nos sitúa ante una doble e interconectada vulnerabilidad y finitud: la vulnerabilidad de las condiciones terrestres de la vida (aire, agua, suelo, etc.) y -dependiendo de ellas- la vulnerabilidad de la especie humana y del resto de las especies vivientes del hábitat terrestre, pues no puede olvidarse que «habitar la tierra es cohabitar siempre con otros seres vivos» (Pelluchon, 2018: 57). Así pues, una ética ecológica que tome como punto de partida ${ }^{9}$ la relación entre ambas formas de vulnerabilidad, que oriente

\footnotetext{
${ }^{4}$ En tal sentido, señala Gómez-Heras que el antropocentrismo «se encuentra en la base de cualquier tipo de racionalidad, sobre todo, de la racionalidad práctica, y que una ética del medioambiente carezca de otro camino de fundamentación que aquel que pasa por la razón humana» (Gómez-Heras, 1997: 52).

${ }^{5}$ Crutzen, P. J. y Stoermer, E. F. (2000). «The 'Anthropocene'». Global Change Newsletter 41: 17-18. Para una consideración de la interacción entre la especie humana, como agente geológico, y La Tierra, así como la necesidad, derivada de la acción geológica humana, de introducción de la justicia en cuestiones medioambientales, puede verse Vicente, Teresa (ed.). Justicia ecológica en la era del Antropoceno. Madrid: Trotta, 2016.

${ }^{6}$ Algunas previsiones científicas avanzan la afectación del cambio climático incluso a generaciones que ya están viviendo, además de a las generaciones futuras virtuales.

${ }^{7}$ «Además de las condiciones bajo las que se da la vida del hombre en la Tierra /.../ los hombres crean de continuo sus propias y autoproducidas condiciones que, no obstante su origen humano y variabilidad, poseen el mismo poder condicionante que las cosas naturales» (Arendt, 2015: 23).

${ }^{8}$ López Bermúdez, Francisco: La interacción Humanidad-Tierra: el Antropoceno, en (Vicente, 2016: 71-124).

${ }^{9}$ Que la vulnerabilidad constituya el punto de arranque de una ética ecológica no implica que sea ese su fundamento: «la debilidad de un ser no constituye -como Jonas cree- el fundamento racional del derecho a recibir protección, como tampoco el poder de protegerlo funda racionalmente el deber de ejercer tal poder» (Cortina, 1990: 34). Otra
} 
la acción humana encaminándola a hacer sostenible la interacción geológica entre los seres humanos y el planeta, ha de tomar en consideración, de modo entrelazado: a) la interdependencia de los seres humanos respecto al marco medioambiental y b) la interdependencia respecto a los otros en el marco social desde el que los seres humanos, desenvolviendo sus vidas, interactúan con el medio ambiente. En tal sentido, propone Leonardo Boff que la ética ecológica ha de retomar las dos fuentes tradicionales de la ética: el ethos como correcto cuidado de la morada o lugar físico preparado como hábitat (ética griega) y la ética entendida como el encuentro con los otros ${ }^{10}$ (ética judeo-cristiana) ( Boff, 2017: 52-54). Se trata, por tanto, de unir la responsabilidad humana para con los otros con la responsabilidad humana para con los seres naturales ${ }^{11}$. Con la atención a estas dos fuentes éticas, que encontramos anudadas en la ética ambiental, una relación ser humano-naturaleza de carácter preservador no puede quedar al margen de las relaciones interpersonales dadas en el marco de instituciones sociales reguladas normativamente..

La ética dialógica, inserta en el denominado giro lingüístico efectuado por la filosofía contemporánea, reconduce estas dos fuentes éticas. Dichas fuentes quedarían, en cierto modo, unidas y absorbidas en el medio lingüístico: el poder de lo intersubjetivo propio del lenguaje se impone a los sujetos (Habermas, 2009: 22-23), posibilitando tanto el acceso al mundo que habitamos ${ }^{12}$ y el establecimiento discursivo de normas morales y jurídicas ${ }^{13}$ para coordinar las acciones con vistas a su correcto cuidado, como un entendimiento con los otros tendente al establecimiento de relaciones interpersonales que descansen en normas legítimas. En la intersubjetividad característica del lenguaje usado por los sujetos se revela: a) la vinculación mutua entre los sujetos, en tanto que, por formar parte de la comunidad lingüística, usan el lenguaje para entenderse entre sí, y b) la dependencia de tales sujetos respecto al acceso lingüístico al mundo compartido que habitan y respecto a la coordinación lingüística de las acciones que desarrollan en él ${ }^{14}$. En palabras de Habermas, «la objetividad del mundo, esta objetividad que suponemos en el habla y la acción, está tan fuertemente imbricada con la intersubjetividad del entendimiento sobre algo en el mundo que no podemos burlar ni ir más allá de este nexo, es decir, no podemos escapar del horizonte de nuestro mundo de la vida intersubjetivamente compartido, un horizonte que se nos abre a través del lenguaje» (Habermas: 2008a: 49-50).

El uso argumentativo del lenguaje remite a una comunidad, a la que pertenecen todos los seres capaces de comunicación lingüística, que se sustenta en el reconocimiento mutuo entre los interlocutores. En tal sentido, para Apel, todos los miembros de tal comunidad de comunicación que usan argumentativamente el lenguaje se reconocen mutuamente como interlocutores con los mismos derechos. De ahí que, para Apel, el principio fundamental de la ética discursiva consista en el reconocimiento recíproco de todos los interlocutores como

cosa distinta, como recuerda Pelluchon (citando a Hans Jonas, 1995), es que reconocemos lo que resulta valioso para nosotros cuando somos conscientes de su vulnerabilidad.

${ }^{10}$ «El otro es cualquier habitante del planeta /.../ El otro son los seres de la naturaleza, los animales, los ecosistemas y la propia Tierra», (Boff, 2017: 54).

11 «El imperativo de la ética de la responsabilidad puede formularse así: "Actúa con tal responsabilidad que las consecuencias de tus actitudes y tus acciones no sean nocivas para el otro ni destructivas para la Naturaleza, la vida y la Tierra», Ibid, p. 61.

12 «El lenguaje dirige nuestra mirada siempre de una determinada manera hacia el mundo. En él está inscrito algo así como una imagen del mundo» (Habermas, 2008: 23).

${ }^{13}$ Habermas hace depender el derecho legítimo del poder comunicativo que, en el medio lingüístico, permite la formación discursiva de la voluntad (Habermas, 2008b: 216-218; 257). Se trata de una concepción procedimental del derecho.

${ }^{14}$ Para Habermas, la acción comunicativa es aquella en la que «los actores coordinan sus planes de acción a través del entendimiento lingüístico» (Habermas, 2011: 117). 
personas (Apel, 1985: 380). Por eso mismo, argumentar en serio, por ejemplo, sobre la exigencia de sostenibilidad ecológica presupone ya siempre tratar de «asegurar la supervivencia del género humano como comunidad real de comunicación», como condición necesaria para realizar la comunidad ideal de comunicación (Apel, 1985: 409). Apel también considera que la relación con los seres de la naturaleza no debe ser interpretada como relación con meras «cosas», puesto que dichos seres tienen un estatus análogo al de los co-sujetos de la comunidad de comunicación ${ }^{15}$. Aunque Habermas, mantiene esta misma concepción de la persona basada en el mutuo reconocimiento que se otorgan los interlocutores del discurso argumentativo, en obras como El futuro de la naturaleza humana o Entre naturalismo y religión introduce también una concepción de la persona como sujeto encarnado: desde el momento del nacimiento, el organismo animal de la especie humana se inserta en un conjunto de relaciones sociales y, a través de una cultura pública constituida lingüísticamente, puede llegar a convertirse en persona (Habermas, 2009: 51-52). Esta concepción del sujeto hablante como sujeto encarnado supone reconocer que junto al posible daño simbólico, que puede afectar a una subjetividad singular emergida a partir de las relaciones intersubjetivas en el proceso socializador, también hay que contar con el posible daño físico causado en un cuerpo (Leib) frágil, tanto por sí mismo como por la dependencia de los demás (Habermas: 2009: 50-51). Por su parte, en su ética cordial Adela Cortina distingue dos tipos de reconocimiento (2005: 152-153). Además del reconocimiento de la persona en tanto que interlocutor válido -real o virtual-, existe una segunda forma de reconocimiento, que consiste en el reconocimiento experiencial del otro como alguien que es «carne de mi carne y hueso de mi hueso». Con ese alguien puedo entablar una relación de igual a igual, una relación -que, en virtud de la comunicación lingüística, puede ser configurada normativamente- muy distinta a la que puede entablarse con animales, plantas u otros seres naturales. Se trata de un vínculo vivencial entre aquellos que se reconocen mutuamente como personas, es decir, como seres con igual dignidad aunque también, al tener en común un mismo tipo de corporalidad, compartiendo la corporalidad humana, se reconocen asimismo como seres siempre vulnerables (Cortina: 2009a: 122-126). Este carácter vulnerable es compartido también por el resto de los seres naturales, por lo que la relación con ellos exige establecer normas protectoras legítimas, pues «no hay "buenas razones" para dañar a un ser vivo /.../ si tal daño es evitable» (Cortina, 1990: 33).

De este breve apunte sobre la ética discursiva podemos entresacar, pues, que es el reconocimiento mutuo de la igual dignidad entre sujetos capaces de lenguaje, los cuales -en virtud de su condición corpórea- se reconocen asimismo como seres vulnerables, lo que nos vincula moralmente a los otros. Tal reconocimiento entre seres que son cuerpo (Habermas, 2008a; 2009; MacIntyre, 2001), que son de carne y hueso ${ }^{16}$, y, por tanto, vulnerables, ha de suponer también el reconocimiento de estar vinculados a un medio ambiente, socialmente configurado, que sustenta materialmente las posibilidades de supervivencia biológica y que, por tanto, es condición de posibilidad de los proyectos biográficos. En consecuencia, el daño ${ }^{17}$ que, como resultado de la acción humana, está afectando actualmente al medio ambiente global, en la medida en que supone una amenaza a las condiciones materiales de la vida (el aire, el agua, el suelo, etc.), acentúa la vulnerabilidad física y la finitud de la especie humana (tanto la existente actualmente como la de futuras generaciones), así como la de todas las especies vivientes con

\footnotetext{
15 «Nos relacionamos con los seres de la naturaleza como algo que es parecido o análogo a los cosujetos humanos de la comunicación» (citado por Juan Carlos Siurana, op. cit.)

16 «Como somos seres de carne y hueso y la existencia tiene una materialidad y un peso, nuestra vida siempre se ve desbordada por la de los demás» (Pelluchon, 2018:58).

${ }^{17}$ Nos referimos a los grandes daños que actualmente afectan al medio ambiente (cambio climático, contaminación atmosférica, residuos, deforestación, pérdida de biodiversidad, etc.). Cfr. Juan Carlos Siurana, La sociedad ética, Cânoves y Samalús: Proteus, 2009.
} 
las que compartimos nuestra condición terrestre. Si estamos obligados moralmente a no dañar y a beneficiar a los otros, en virtud de la ligazón que nos une al conjunto de la humanidad (Cortina, 2009a), entonces constituye una exigencia moral que, por estar ligados los seres humanos -en virtud de su corporalidad- al medio ambiente, en tanto que este es condición humana, debamos estar moralmente obligados a no dañarlo (principio de no maleficencia) y a usar responsablemente (Jonas, 1995; Apel 1985) el poder humano, en el contexto tecnológico actual, para el sostenimiento del hábitat terrestre, en el que tanto los seres vivos como la humanidad se desenvuelven. La clave de tal exigencia moral, que ha de quedar trasladada al ámbito jurídico, no radica únicamente en salvaguardar el derecho humano a las condiciones medioambientales necesarias para una vida digna, sino también en el reconocimiento del valor interno de los seres vivos y de la Tierra: el fundamento del trato moral a los seres vivos y a la Tierra estaría en su carácter valioso y vulnerable (Cortina 2015: 60-64).

\section{DAÑO AMBIENTAL, RECONOCIMIENTO MUTUO Y PRINCIPIO DE NO MALEFICENCIA}

En virtud de esa doble interdependencia -de los seres humanos entre sí y de estos con el hábitat terrestre-, entendemos, según pone de relieve la ética discursiva, que resulta relevante la categoría de reconocimiento mutuo en la ética ambiental. Tal relevancia quedaría patente tanto en lo que se refiere, negativamente, a los fenómenos de degradación ambiental provocados por la acción humana, como en lo que respecta, en sentido positivo, a la protección normativa del medio ambiente. Fijándonos ahora en la acción humana degradante (contaminación, explotación abusiva, destrucción, etc.), debe interpretarse el daño medioambiental evitable provocado por el ser humano como un perjuicio causado en su propio valor a la naturaleza, a los animales o a las plantas, con repercusión en los seres humanos. Si consideramos que dicho daño evitable viene precedido de una instrumentación de la naturaleza y de los seres vivos, entonces puede decirse que tiene un origen en la adopción de una actitud de cosificación en la que se produce un olvido del reconocimiento de los otros: «percibimos a los animales, las plantas o las cosas solo identificándolos como cosas, sin tener presente que poseen una multiplicidad de significados existenciales para las personas que nos rodean y para nosotros mismos» (Honneth, 2005: 104). Desde el punto de vista de la ética discursiva, este olvido indirecto del reconocimiento de los otros puesto de manifiesto por Honneth estaría obturando la incorporación de tales significados existenciales (tradiciones, conocimientos, valores, etc.), traducidos en forma de argumentos, en caso de realización de debates en los que se deliberara, con una finalidad normativa, acerca de cuestiones ecológicas (Pelluchon, 2015: 121-128). No obstante, el daño ambiental evitable, interpretado en el sentido de un trato a la naturaleza o a los seres vivos como meras cosas carentes de valor, no conlleva únicamente un olvido indirecto de los significados que los otros les atribuyen. Implica también, en sentido fuerte, una negación directa del reconocimiento de la dignidad y del carácter vulnerable de las personas afectadas por las consecuencias de tal daño en sus vidas. El reconocimiento de los otros, actuales o futuros, supone tomar conciencia de que su vulnerabilidad está también ligada a una medio ambiente cada vez más desequilibrado por la acción humana. En consecuencia, es necesario extender la aplicación del principio bioético de no maleficencia, procedente de la bioética médica, al ámbito de la ética medioambiental ${ }^{18}$. En este principio ecológico, entendido como freno normativo al daño evitable provocado por el ser humano a la vida y a sus condiciones abióticas, subyace una doble consideración:

\footnotetext{
${ }^{18}$ Tal principio deontológico, de carácter prioritario, está a la base, por ejemplo, del principio de precaución recogido en la Declaración de Rio ( Capó y Drane, 2014).
} 
a) el reconocimiento de la mutua vulnerabilidad humana. La filósofa norteamericana Martha Nussbaum ha denunciado el mito de la invulnerabilidad, como pretensión de autoocultamiento de la condición humana, caracterizada por la mortalidad y la finitud (Nussbaum, 2006: 355-364). La conciencia ecológica, centrada en alertar sobre la necesidad de prevenir y evitar el daño medioambiental, refuerza nuestra autocomprensión como seres corporales vulnerables -en tanto que individuos y en tanto que humanidad- que requieren protección normativa, moral y jurídica, en las relaciones intersubjetivas sobre el trasfondo del mundo de la vida compartido. La conciencia de esta mutua vulnerabilidad -proyectada también en las generaciones del futuro- genera una solidaridad (Fraser, 2008: 261) sustentada en el mutuo reconocimiento ${ }^{19}$.

b) el reconocimiento de la vulnerabilidad intrínseca de los seres naturales. Tal reconocimiento queda patentizado en el valor que les atribuimos, especialmente cuando advertimos que están amenazados (Pelluchon, 2015: 192). De ahí procede la exigencia para la aplicación del principio de reparación del daño y del principio de causación (Vicente, 2016), a los que los sujetos se obligan recíprocamente.

Dado que el principio de no maleficencia no tiene un carácter absoluto sino proporcionado (Gracia, 2004: 225-242), en los conflictos surgidos entre la atención a los seres humanos y la atención al medioambiente, se requiere tener en cuenta las circunstancias y las consecuencias, es decir, hay que recurrir al principio de responsabilidad.

\section{PRINCIPIO DE RESPONSABILIDAD Y RECONOCIMIENTO MUTUO}

Si nos fijamos ahora en el establecimiento, de acuerdo con el principio de responsabilidad, de normas morales y jurídicas protectoras del medio ambiente, habría que decir que tales normas responderían tanto a la salvaguarda del valor intrínseco que poseen la naturaleza, las plantas o los animales, como también a la protección del derecho humano a un medio ambiente equilibrado. Esta responsabilidad humana por el futuro del hábitat natural -que ha de quedar traducida en normas universales, por la dimensión macroética de la problemática ecológica (Apel, 1985)-, inseparable de la responsabilidad por el futuro de la humanidad, proviene tanto de la mencionada interacción geológica seres humanos-Tierra como del privilegio que suponen las capacidades cognitivas de los seres humanos (Pelluchon, 2015). De tal responsabilidad, que remite a un conocimiento humano que posibilita explicar lo que ocurre en la naturaleza y las consecuencias que tienen en ella nuestras acciones, depende poder transformar la interacción seres humanos-Tierra en una interacción sostenible. Es la

\footnotetext{
${ }^{19}$ La ética neoaristotélica (MacIntyre, Nussbaum) critica la concepción contractualista de la justicia en relación a las personas con diversidad funcional, basándose en que el contrato dejaría fuera a quienes están en circunstancias biopsíquicas desiguales (Nussbaum, 2007), en que no existe una proporcionalidad exacta entre lo que se da en el cuidado a otro y lo que, en el futuro, se podrá recibir de otro distinto (MacIntyre, 2001). Ambos autores, que rechazan la idea de beneficio mutuo, reivindican un trato justo pese a las asimetrías en que se encuentran tales personas. Por su parte, la ética discursiva apela a la idea de reconocimiento mutuo en la anticipación contrafáctica de la comunidad ideal de comunicación (Apel) o en la situación idealizada de habla (Habermas), frente al mero contractualismo. En el caso analógico de los derechos ecológicos de las generaciones futuras -en el que tampoco hay reciprocidad directa ni puede contarse con una proporcionalidad exacta entre el estado del mundo natural que se recibe y el que se entrega-, la ética discursiva asume advocatoriamente la representación de tales interlocutores virtuales en la comunidad ideal de comunicación (Apel) o en la situación ideal de habla (Habermas), como exigencia para que el diálogo racional mantenga la simetría y el resultado alcanzado pueda tener validez (Pelluchon también asume el papel de la ética discursiva en el ámbito ecológico). Si tenemos en cuenta la ética cordial de Cortina, su planteamiento remitiría, previamente a dicha idealización, al reconocimiento cordial, compasivo, con los seres humanos de las generaciones futuras, en tanto que pertenecientes a una humanidad común, en los que proyectaríamos una igual dignidad y vulnerabilidad.
} 
sostenibilidad de tal interacción lo que permitirá la salvaguarda del hábitat terrestre y de las especies vivientes en él, para transmitirlo en las mejores condiciones posibles a las generaciones futuras. Como pone de relieve la ética del diálogo (Apel, Habermas), la corrección de tales normas -cuya efectividad para el logro de la sostenibilidad medioambiental queda sustentada, a su vez, en la validez del conocimiento acerca del intrínseco dinamismo de la naturalezadescansa en el reconocimiento de los otros como personas, es decir, como interlocutores válidos (reales o virtuales), en tanto que estos pudieran dar su consentimiento a las mismas en el discurso: «Toda norma válida tendría que poder recibir la aquiescencia de todos los afectados tan pronto estos participasen en un discurso práctico» (Habermas, 2000: 36).

Un breve análisis de lo supuesto en la aplicación del principio de responsabilidad, según es formulado por la ética discursiva ${ }^{20}$, muestra que el reconocimiento mutuo está implicado en los siguientes aspectos:

a) Aspecto epistémico. En una primera dimensión, la responsabilidad humana con la naturaleza y los seres vivos requiere disponer de un adecuado conocimiento de los procesos naturales y de la incidencia de la acción humana en los mismos. En dicho conocimiento confluyen no solo las aportaciones proporcionadas por científicos expertos en sus campos disciplinares, sino también el conocimiento, experto o lego, aportado por el resto de miembros de la comunidad (ecologistas, políticos, juristas, filósofos, ciudadanos, etc.). Como propone Pelluchon (2015: 121-128), la articulación de todos estos conocimientos constituirá el punto de partida para la elaboración de los argumentos que habrán de exponerse en la deliberación democrática sobre temas ecológicos. La argumentación constituye la base ético-política para el establecimiento de normas jurídicas válidas, que respondan al poder comunicativo del que también participan los ciudadanos en un sistema democrático ${ }^{21}$. Ahora bien, este saber sobre el medio ambiente, como base epistémica para un cuidado y protección que puedan resultar efectivos, no se agota, como pone de manifiesto Habermas, en la pura objetivación del mundo natural compartido, desde la perspectiva adoptada por la racionalidad teórica de cada uno de los diferentes observadores. Dada la mediación lingüística del conocimiento del mundo natural compartido, es necesario conectar «la objetividad del mundo /.../ con la intersubjetividad del entendimiento entre participantes en la comunicación» (Habermas, 2008, 42-43). Se requiere, por tanto, dar prioridad a la perspectiva intersubjetiva de los participantes en las prácticas comunicativas, en las que se intercambian argumentos para llegar a un entendimiento sobre el mundo natural compartido. Las pretensiones de validez veritativa de un conocimiento que es falible, descansan, según Habermas, en el reconocimiento intersubjetivo de la comunidad de quienes argumentan para cerciorarse de tal verdad (Habermas, 2008a: 50-51).

b) Aspecto valorativo. Una segunda dimensión de la responsabilidad humana por el medio ambiente se relaciona con la estimación de su carácter valioso. Aducir el valor intrínseco

\footnotetext{
${ }^{20}$ En tal sentido, Cortina defiende la adecuación de la ética discursiva para enfrentar los retos ecológicos al aportar los elementos necesarios: «un concepto de racionalidad práctica universal, irreductible a la racionalidad tecnológica, pero capaz de cooperar con ella; la responsabilidad por el futuro y la solidaridad como virtud», (Cortina, 1990: 36).

${ }^{21}$ En la concepción procedimental-deliberativa de la democracia propuesta por Habermas (2008b) se tiene en cuenta tanto los debates procedentes de la opinión pública como los debates formales del sistema político representativo. Corine Pelluchon, coincidiendo en parte con Habermas, formula tres niveles de lucha política para la protección de los animales: un nivel normativo, propio de una cultura política que establezca como finalidad tal protección, reflejado constitucionalmente; un nivel representativo, que incluya representantes de los intereses de los animales, y un nivel cultural de acción política, susceptible de transformarse en partido político, que forme una opinión pública favorable a la causa animal. Por su parte, Daniel Innerarity señala los problemas que tiene una democracia electoral, ligada al cortoplacismo, para convertirse en una verdadera democracia ecológica (http://ctxt.es/es/20180207/Firmas/17764/Daniel-Innerarty-democracia-sufragio-voto-elecciones.htm; consultado el 13/02/2018). También entiende que un sistema democrático es deficiente si no integra en él a los sujetos no humanos y a la naturaleza (El país, 30-3-2018).
} 
de los seres naturales no implica necesariamente un compromiso con la existencia de valores naturales (Pelluchon, 2015: 81-87). En tal sentido, no puede confundirse el valor que tienen los seres naturales con la propia naturaleza, las plantas o los animales. Para Cortina, los valores son cualidades reales de las personas, las cosas o los seres naturales que los seres humanos reconocemos, descubrimos, Por tanto, los valores hacen referencia a la relación entre tales cualidades reales y los seres humanos que realizan dicho reconocimiento: «hacen falta seres capaces de estimar las cualidades valiosas o el valor que radica en los seres valiosos» (Cortina, 2009b: 177). Podemos hablar, pues, del carácter internamente valioso de los seres naturales en tanto que los seres humanos aprecian dicho valor. Este carácter intrínsecamente valioso, no meramente instrumental, radica en que permiten «acondicionar el mundo, haciéndolo habitable» (Cortina, 2009a: 144), porque constituyen aquello de lo que no podemos prescindir porque entonces se perdería algo importante (Gracia, 2013: 241). Diego Gracia ha defendido que los valores colectivos -por ejemplo, los valores ecológicos- existentes en la cultura no son ni objetivos ni subjetivos, sino que son intersubjetivamente construidos ${ }^{22}$ a través de un proceso deliberativo, en el que también intervienen, además de lo cognitivo, las emociones. A partir de esta deliberación moral, que construye y da razón de nuestros valores, surgirá la deliberación político-jurídica, con el fin de que tales valores sean realizados mediante normas legítimamente establecidas. Este carácter intersubjetivo del valor intrínseco que para nosotros tienen la naturaleza y los seres naturales presupone, pues, el reconocimiento de los participantes en dicho proceso deliberativo.

c) Aspecto normativo La responsabilidad humana por el mundo natural ha de quedar plasmada, en una dimensión final, en un conjunto normativo moral y jurídico, tendente a una adecuada protección del mismo. Tales normas han de ser entendidas como concreciones del derecho humano a un medio ambiente equilibrado, proyectado hacia las generaciones futuras, de modo que obliguen a compartir la Tierra y sus recursos con los otros (Vicente, 2016: 23-27). El consenso sobre las mismas, basado en la fuerza de los mejores argumentos, es posible en la medida en que no responden a intereses particulares, ya que existe un interés generalizable en el mantenimiento y la continuidad de la humanidad. Dichas normas expresan las obligaciones fundamentadas en la racionalidad discursiva práctica- de no excluir a ningún interlocutor virtual válido ni dejar al margen ninguna de sus exigencias que sean transmitidas argumentativamente (Apel, 1985: 403-404). La validez de tales normas, de acuerdo con el canon crítico propuesto por la ética discursiva, reside en la posibilidad de aceptación de las mismas por parte de todos los afectados (actuales o virtuales). Así pues,, los afectados de las generaciones futuras también han de ser reconocidos como personas, es decir, como interlocutores válidos, $\mathrm{y}$, por tanto, sus intereses han de ser representados advocatoriamente. Lo cual exige una concepción descentrada del sujeto, es decir, un sujeto que sea consciente de que la vulnerabilidad medioambiental afecta tanto a la humanidad actual como a la de las generaciones del futuro: «un sujeto que no es solamente un "yo primero" o un "después de mí el diluvio" (Pelluchon, 2015: 194). Cortina entiende que dicho sujeto responsable ha de tener un carácter dispuesto al reconocimiento: a) que someta a crítica racional sus intereses y convicciones; b) que tenga predisposición a reconocer los derechos de los demás; c) comprometido con una justicia basada en argumentos y d) que intente llegar a consensos sobre intereses generalizables. (Cortina, 2009a: 210-213). La configuración de este carácter moral es necesaria para que se tengan en cuenta también los intereses relativos a un marco medioambiental equilibrado, que las generaciones futuras comparten con las generaciones actuales. Cortina (2009a: 236) propone como criterio material de justicia, compatible con el criterio procedimental discursivo para el establecimiento de normas legítimas, el criterio del mínimo decente para empoderar a las personas y que puedan

\footnotetext{
${ }^{22}$ Diego Gracia, op. cit.
} 
llegar a ser interlocutores válidos. Este mínimo decente ha de ser ecológicamente sostenible, para posibilitar las generaciones futuras de interlocutores reales.

Por otra parte, también hay que tener en cuenta que un humanismo ecológico capaz de conjugar la dignidad humana con el cuidado correcto de la naturaleza, también ha de concebir la responsabilidad humana respecto a la naturaleza desde la perspectiva de la protección de su valor interno. Para un antropocentrismo responsable, la naturaleza, las plantas o los animales son valiosos y vulnerables, por lo que tenemos obligación de protegerlos (Cortina, 2009a: 240243) y de educar a las personas en actitudes de no dañarlos (Cortina, 2009b). Corine Pelluchon $(2015 ; 2018)$ da un paso más allá y considera que los animales, sin ser ciudadanos, son sujetos políticos que deben tener representados sus intereses en una democracia deliberativa que elabore normas jurídicas que favorezcan la conciliación de sus derechos con los derechos humanos (Pelluchon, 2018). En tal caso, esta autora estaría incluyendo a los animales (lo que es extensible al medio natural y a las plantas) como afectados (al menos, analógicamente) por las normas humanas. Lo que supone que han de ser representados advocatoriamente en las instancias políticas deliberativas. En tal caso, también se exige el reconocimiento de dichos representantes, con el fin de que las normas jurídicas establecidas, sean de carácter constitucional o de carácter legislativo, respondan a la consideración (Pelluchon, 2015: 264267) de los intereses de los seres naturales, en tanto que seres valiosos y vulnerables.

\section{CONCLUSIÓN}

En este trabajo hemos pretendido defender la que la noción hegeliana de reconocimiento recíproco, recogida por la ética discursiva, resulta relevante para la fundamentación de obligaciones ecológicas requerida por la ética medioambiental. La ética discursiva, surgida filosóficamente a raíz del giro lingüístico, traduce en el poder intersubjetivo del lenguaje las dos fuentes primarias en las que ha de apoyarse una ética ecológica: el correcto cuidado de la Tierra como morada en que habita -al menos, hoy por hoy- la humanidad y el trato justo con los otros. La necesidad de la ética medioambiental se acentúa por la huella geológica que los seres humanos dejan en su interacción con el medio terrestre y los seres vivos, con el entrelazamiento entre la vulnerabilidad propia de los seres corporales individuales y la vulnerabilidad sobre el conjunto de las especies vivas, incluyendo a la especie humana. Dicha ética viene sustentada, entre otros, sobre los principios de no maleficencia y de responsabilidad. Ambos principios remiten al reconocimiento intersubjetivo de seres que tienen lenguaje y que han de responsabilizarse en sus acciones del mundo de la vida que comparten. Las amenazas al conjunto de la Humanidad y a lo valioso que encontramos en los seres vivos y en sus condiciones (aire, agua, suelo, etc.) ponen en peligro un mundo habitable. Habitable no solo en el sentido de que facilite la supervivencia, sino un mundo en el que, protegiendo lo valioso desde un marco de justicia con los otros con los que compartimos tal hábitat, pueda desarrollarse una vida más plena.

\section{BIBLIOGRAFÍA}

- APEL, K. O., La transformación de la filosofía, II. Barcelona: Taurus, 1985.

- AREnd, H., La condición humana, Barcelona: Paidós, 2015.

- Capó, M. A., Drane, J., "Planteamientos Bioéticos del Medio Ambiente", en Revista Bioethikos, 8 (1), 2014, pp. 46-52. 
- Cortina, A., "Ecologismo y derechos de los pueblos", en Claves de razón práctica, 8, 1990, pp. 28-36.

- Cortina, A., Alianza y Contrato, Madrid: Trotta, 2005.

- Cortina, A., Ética de la razón cordial, Oviedo: Ediciones Nobel, 2009a.

- Cortina, A., Las fronteras de la persona, Madrid: Taurus, 2009b.

- Cortina, A., ¿Para qué sirve realmente la ética?, Barcelona: Paidós, 2015.

- Fraser, N., Escalas de justicia, Barcelona: Herder. 2008.

- GARcíA- MARZÁ, D., "La responsabilidad ecológica de la empresa: el punto de vista de la ética empresarial", en González, Elsa (ed.), Ética y ecología. La gestión empresarial del medio ambiente, Castelló de la Plana: Publicacions de la Universitat Jaume I, 1999.

- Gómez-Heras, J. Mª. Ga., (coord.), Ética del medio ambiente. Problemas, perspectivas, historia, Madrid: Tecnos, 1997.

- Gracia, D., Como arqueros al blanco. Estudios de Bioética, Madrid: Triacastela, 2004.

- GRACIA, D., Valor y precio, Madrid: Triacastela, 2013.

- Habermas, J., Aclaraciones a la ética del discurso, Madrid: Trotta, 2000.

- Habermas, J., Entre naturalismo y religión, Barcelona: Paidós, 2008a.

- Habermas, J., Facticidad y validez, Madrid: Trotta, 2008b.

- Habermas, J., El futuro de la naturaleza humana. ¿Hacia una eugenesia liberal?, Barcelona: Paidós. 2009.

- Habermas, J., Verdad y justificación, Madrid: Trotta, 2011.

- Honneth, AL., Reificación, Buenos Aires: Katz, 2005.

- Jonas, H., El Principio de Responsabilidad: ensayo de una ética para la civilización tecnológica, Barcelona: Herder; 1995.

- Macintyre, A., Animales racionales y dependientes, Barcelona: Paidós, 2001.

- Nussbaum, M., El ocultamiento de lo humano, Buenos Aires: Katz, 2006.

- Nussbaum, M., Las fronteras de la justicia, Barcelona: Paidós, 2007.

- Pelluchon, C., Elementos para una ética de la vulnerabilidad, Bogotá: Pontificia Universidad Javeriana, 2015.

- Pelluchon, C., Manifiesto animalista, Barcelona: Reservoir Books , 2018.

- Siurana, J. C., La sociedad ética. Indicadores para evaluar éticamente una sociedad, Cânoves y Samalús: Proteus, 2009.

- Vicente, T., (ed.), Justicia ecológica en la era del Antropoceno, Madrid: Trotta, 2016 